\title{
Prevention of neural tube defects by folic acid - awareness among women of childbearing age in Slovakia
}

\author{
Horn $\mathrm{F}^{1}$, Sabova $\mathrm{L}^{2}$, Pinterova $\mathrm{E}^{3}$, Hornova $\mathrm{J}^{2}$, Trnka $\mathrm{J}^{1}$ \\ Department of Paediatric Surgery, Medical Faculty of Commenius University and Children's University Hospital in Bratislava, \\ Slovakia. frantisek.horn@fmed.uniba.sk
}

\begin{abstract}
Background: Folic acid deficiency plays a central role in the aetiology of many congenital anomalies including neural tube defects. Protective effect of folic acid on embryo may be acquired only if taken periconceptionally. Objectives: The aim of the study was to investigate the awareness about folic acid among women of childbearing age in Bratislava, Slovakia.

Methods: There were 130 respondents involved in the research (106 pregnant women, 24 female students of medical faculty). Using questionnaire we acquired following data: pregnancy details, interest in diet before and during pregnancy, recommendations regarding nutrition and supplementation pre- and post-conception, knowledge about folic and other acid in 2004 and 2009.

Results: More than half of the respondents knew the sources of folic acid. The interest in the nutrition facts of the food dropped from $91 \%$ to $58.5 \%$. The number of pregnant women advised about correct nutrition and folic acid supplementation before and during pregnancy increased from $16 \%$ to $37 \%$. Planning the next gravidity with folic acid supplementation became greater than $21 \%$ (38\% in 2009). Nevertheless, only $46 \%$ of these women believed that proper food content with folic acid may prevent congenital anomalies. In a group of students planning to take folic acid periconceptionally the number raised up to $62.5 \%$.

Conclusion: The results revealed low knowledge about the effect of folic acid on developing embryo among women of childbearing age. Effective intervention programs are needed with the aim to improve periconceptional intake of folic acid in 2004 and 2009. The results in both periods show low knowledge about this essential vitamin (Tab. 1, Fig. 8, Ref. 31). Text in PDF www.elis.sk.

Key words: neural tube defects, folic acid, prevention.
\end{abstract}

Congenital malformations are somatic defects present in a child at birth. They occur in $2-3 \%$ of newborns and represent one of the leading causes of neonatal and infant morbidity and mortality. Congenital malformations may effect various organs. The structure development is either stopped, delayed or directed in the wrong way in early embryonic stage. Causes of congenital malformations may be inherited or acquired (as fetal exposure to infections, toxic substances or radiation etc).

Neural tube defects (NTDs) are the second most common birth defect. Current research highlights the important role of folic acid deficiency in the aetiology of neural tube defects and some other congenital malformations.

\section{Definition, occurrence and classification of NTDs}

The term neural tube defect applies to malformation of the embryonic brain and/or spinal cord. In Slovakia annually 5 per

\footnotetext{
${ }^{1}$ Department of Paediatric Surgery Medical Faculty of Commenius University and Children's University Hospital in Bratislava, Slovakia, ${ }^{2} 1$ st Department of Paediatrics Medical Faculty of Commenius University and Children's University Hospital in Bratislava, Slovakia, and ${ }^{3}$ Paediatric Department Vranov, Slovakia

Address for correspondence: F. Horn, MD, PhD, Department of Paediatric Surgery Medical Faculty of Commenius University and Children's University Hospital, Limbova 1, SK-833 40 Bratislava, Slovakia. Phone: +421.905269179
}

10000 live births are affected with congenital malformation of central nervous system. Worldwide it is one child with neural tube defect per 1000 live births $(1,2)$.

McComb classified neural tube defects to open spinal, closed spinal and cranial defects (3). According to the main defect NTDs could be divided into open and closed, cranial and caudal (4). The major defect of spina bifida is the cleft in vertebral arch. Spina bifida alone is not a neural tube defect but accompanies all open and up to 80 to $90 \%$ of closed NTDs (4).

Open defects represent more serious form of NTDs, where part of neural tube is left uncovered by the skin or protrudes from the spinal column and causes neurodeficiency. In the literature, open defect in the caudal neural tube (lumbal or sacral region) is called spina bifida aperta. Craniorachischisis totalis is a total defect of neurulation (development of the brain and spinal cord) and is not compatible with life. Patients with meningo(myelo) cele include individuals with failure of the posterior neural tube closure. Defect of the spinal cord consist of unfused vertebral arches, pedicles are located laterally and the spinal canal is expanded. In the myelocele neural tube is exposed on the surface and has no sac (no covering of meninges) and is situated in the level of the skin. Meningocele's sac is composed of anomalous meninges containing spinal fluid. If the sac contains nerves or spinal cord, it is called meningomyelocele (Figs 1 and 2) (5). Most patients with lesions located lower in the spinal cord can 


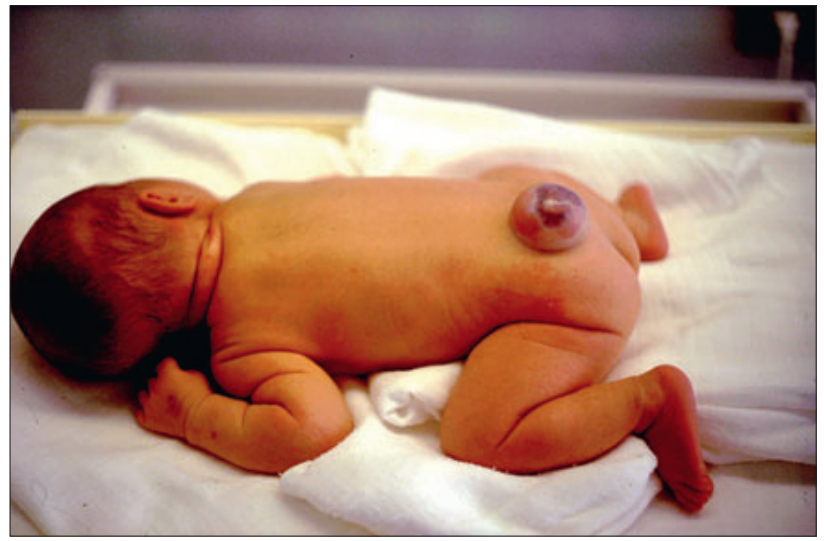

Fig. 1. Newborn with meningomyelocele.

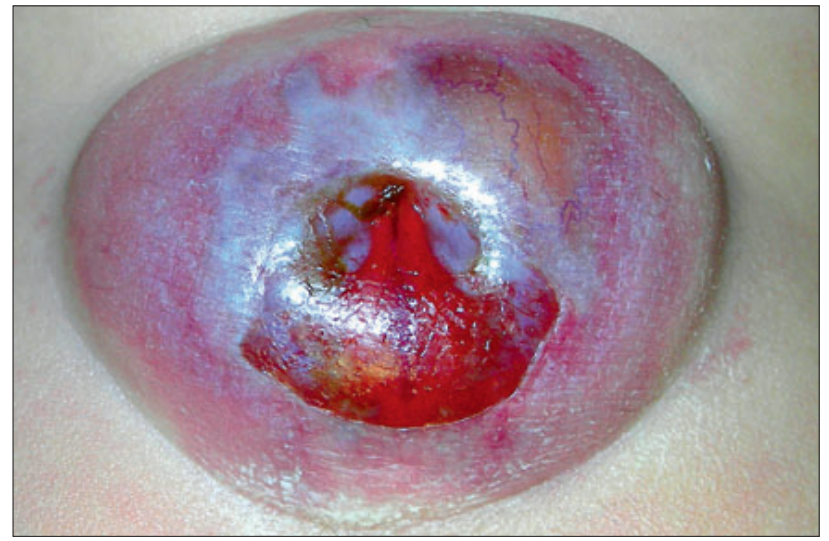

Fig. 2. Open neural plate of meningomyelocele.

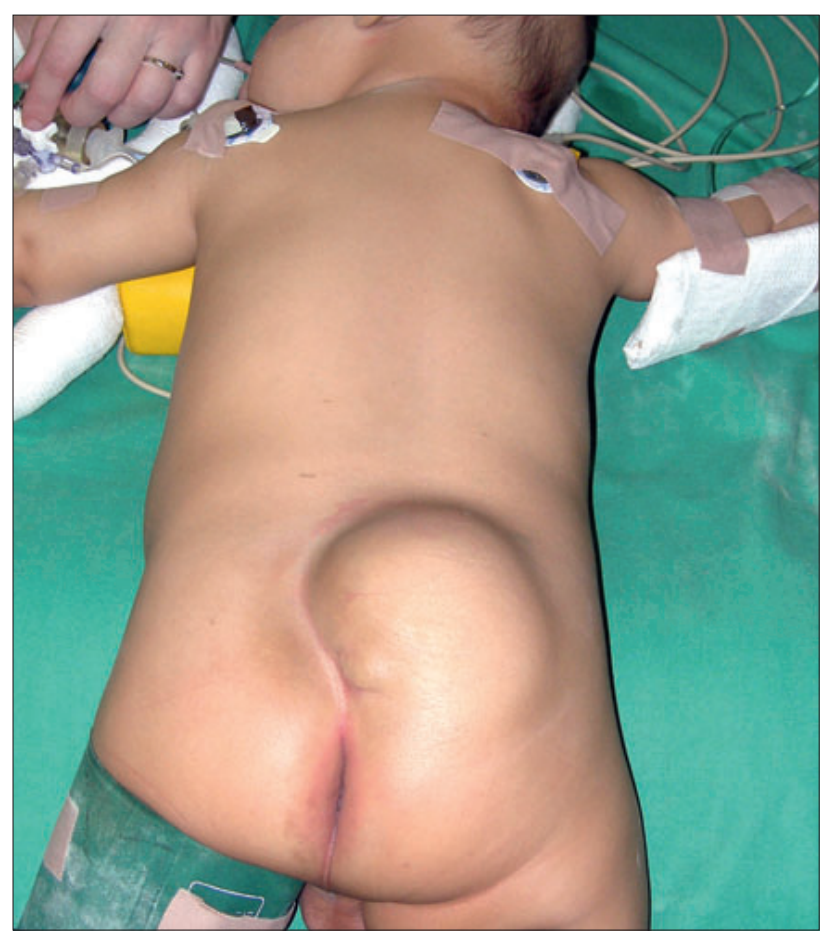

Fig. 3. Child with lipoma.

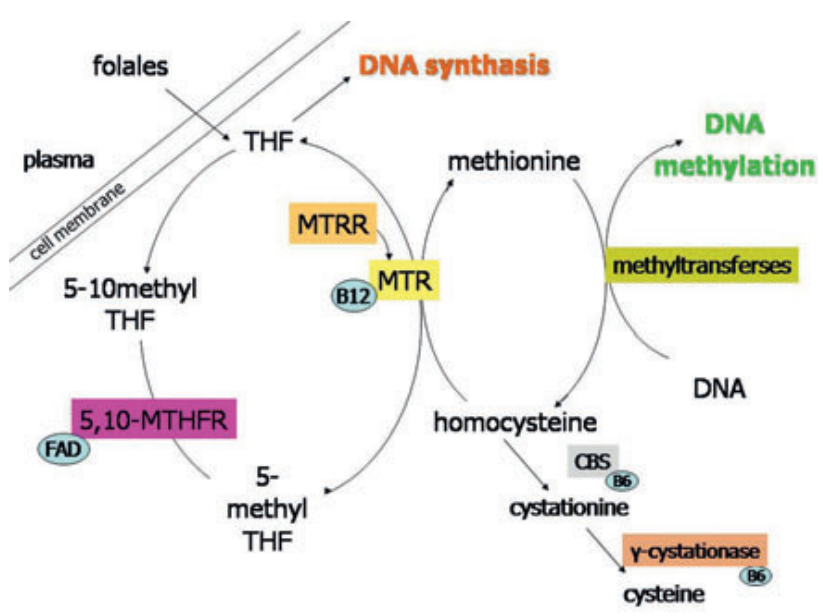

Fig. 4. Folic acid metabolism. THF: tetrahydrofolate; 5,10-methylenTHF: 5,10-methylentetrahydrofolate; 5,10-MTHFR: 5,10-methylenetetrahydrofolate reductase; 5-metylTHF: 5-methyltetrahydrofolate; MTR: methioninsynthase; FAD: flavinadenin dinucleotide; B6: vitamine B6; B12: vitamine B12; MTRR: methioninsynthase reductase, CBS: systationine $\beta$-synthase

walk without assistance, while those with a lesion located above are largely immobile (6). Hydrocephalus occurs almost in all patients with open NTDs.

Closed NTDs are covered by the skin of the back, but $80 \%$ of those located in the lumbosacral area present with lesion of the skin in form of accumulation of hair, pigmented naevus, cutaneous dimples or other. Although the neurological deficiency in infants is usually not present, they may have motor or sensory impairment of the lower extremities or abnormalities of the sphincters as well. Closed NTDs are known as spina bifida occulta and spina bifida cystica. Spinal lipomas - lipomatous malformations of the spinal cord are a common cause of cord tethering that can lead to progressive neurological defects (Fig. 3).

Anencephaly is a disorder of cranial closure of the neural tube. Frontal and parietal bones and squamous parts of occipital bone are usually missing, resulting in bare nervous tissue. Most children with this disorder die before or during delivery. Those born alive can survive only for a couple of weeks.

Encephalocele is probably a defect arising after the closure of the cranial neural tube (7). It occurs in the occipital (70 to $80 \%$ of cases), frontal, at least often in the parietal, or temporal region (7).

\section{Embryogenesis}

Neurulation (development of the central nervous system) in humans occurs in two phases, a primary and a secondary phase. Primary neurulation refers to folding of an induced neural plate that occurs on the dorsal side of the embryo and results in the formation of the brain and spinal cord. Secondary neurulation refers to sequential processes of canalization and retrogressive differentiation of a massive neural cord, and results in the development of the caudal part of the spinal cord. Thus, neural tube formation is initiated by neural folding and completed by canalization. 
Primary neurulation begins during the third week of embryonal life when fetal ectoderm of the shield thickens between pharyngeal membrane and primitive Hensel junction. Neural plate is formed by ectoderm coarsening. Cranial end extends to the sides, caudal end is narrower. Neural plate invaginates along its central axis to form the neural groove, with neural folds on each side. Gradually, the neural folds approach each other in the midline and fuse, converting the neural groove into a neural tube. The fusion begins approximately in the region of the future neck and proceeds in the cranial and caudal directions (beginning of the 4th week of development). Primitive neural tube communicates with the amnionic cavity by way of the cranial (anterior) and caudal (posterior) neuropores. Cranial neuropore closes on the 25 th to 26 th day, whereas closure of the posterior neuropore occurs about two days later.

As the neural tube separates from the surface ectoderm, the neural crest cells migrate to the sides of the neural tube. The neural crest separates into the right and left part, and migrates to dorsolateral aspects of the neural tube, giving rise to the sensory ganglia of the spinal and cranial nerves. Extended cranial end of the neural tube represents the brain and narrower dorsal part represents basis for spinal cord (8).

Neural tube defects occur when various parts of the neural tube fail to close in embryos 21 to 28 days after conception.

\section{Aetiology of NTDs}

Development of the neural tube is a multi-step process controlled by genes and modulated by a number of environmental factors. It involves gene-gene, gene-environment and gene-nutrient interactions. Despite years of intensive research, the exact aetiology of NTDs remains rather complex and poorly understood. It is generally agreed that most NTD cases are of multifactorial origin (9).

NTDs may occur along with congenital heart defects, anus and rectum malformations, omphalocele, tracheoesophageal fistula, diaphragmatic hernia or bladder extrophy. The highest coincidence (up to $25 \%$ ) is in patients with anorectal malformation $(10,11)$ and in children with cloacal extrophy (even up to $100 \%$ ) (12). On the other hand concomitance of NTDs with similar anomalies such as orofacial clefts or gastroschisis has not been reported.

\section{Environmental causes of NTDs}

Incidence of NTDs is dependent on the geographic areas, socioeconomic status etc. Among the environmental risk factors McLone included: agricultural chemicals, pesticides, cleaning agents and disinfectants, radiation, anaesthetics, nursing, solariums, saunas and fever (increased body temperature), lead, tobacco smoking and obesity $>100 \mathrm{~kg}$ (13). Some drugs, especially folic acid antagonists (anticonvulsants, trimethoprim, triamterene and others) significantly increase the risk of NTDs in children of women receiving above mentioned therapy in critical period of development. Folic acid deficiency in diet of women at childbearing age was proven as an independent risk factor for NTDs by large interventional trials.

\section{Genetic causes of NTDs}

Neural tube defects exist in isolation in most cases. Genetic causes of NTDs are associated with several point mutations (e.g. cerebrocostomandibular syndrome, Waardenburg syndrome, Fraser syndrome, Meckel-Gruber syndrome) and chromosomal aberrations (trisomy 13 and 18).

Familial occurrence is constantly subject to study. Parents of children born with NTDs are at risk of having subsequent pregnancy complicated by the presence of neural tube defect 10 to 20 times higher. If there is a relative in wider family with the history of NTD, the risk for malformation is 5 to 10 times higher. According to some authors, the parent with NTD does not have higher risk of giving birth to a child with NTD in comparison to the rest of the population.

Swain et al. (1994) focused on congenital malformations in newborns in terms of order of pregnancy. The babies born to mothers of gravidity 4 or more had significantly higher incidence of congenital malformations (40\% of them affecting the CNS) when compared to mothers of lower gravidity (14). It is known that defects in several genes place the embryo at risk of faulty neural tube closure. However, we do not know of any gene that would be independently responsible for NTDs in humans $(7,15)$.

Experimental models are often used to illustrate the early stages of embryonic development. The aetiology of NTD is studied mostly on mouse models. In the beginning of spinal cord development $W n t$ signaling pathway accounts for dorsalization and posterioration of neural plate, midbrain development and organization of dorzovertebral somites. Hedgehog pathway plays similar role. Hedgehog induces neural tube plates and notochord and dorsoventral organization of neural tube. Zero mutations of hedgehog receptor in mice cause spinal defects and open neural tube defects (17). $H O X$ and $P A X$ transcription factors take part in neural tube closure. Genes for these proteins were also studied as candidate genes for NTDs in human (9). Neurulation is controlled and driven by convergent extension through the planar cell polarity (PCP) pathway (non-canonical Wnt/frizzled pathway) (17). Genes in the PCP pathway include Frizzled (Fz), Dishevelled (Dsh), Flamingo (Fmi), Prickle (Pk), Diego (Dgo) and Strabismus/VanGogh (Stbm/Vang) (18). Gene mutations for VANGL 2 in loop-tail mice, which caused craniorachischisis were, also studied for potential role in NTDs in human, however, with various results $(19,20)$.

\section{Interaction of genotype and environment}

Folic acid deficiency is an important factor causing NTDs and other congenital malformations (congenital heart defects, malformations of the urinary tract, limb malformations and others). Folic acid and folates are necessary for producing and maintaining proper DNA structure, DNA methylation, cell division especially in rapidly dividing cells (bone marrow, embryonic cells and other). Folic acid deficiency may cause megaloblastic anemia, vascular disease or cancer, particularly when combined with mutations/ polymorphisms in enzymes of folic acid cycle. The incidence of 
NTDs depends on presence of mutant alleles in different populations, but also on factors such as lifestyle, intake of micronutrients not only during first trimester of pregnancy, but also before conception. Different genotypes interact together with diversity of eating habits in determining the risk for NTDs in the offspring. Low folate and vitamin B12 level in mothers of children with NTDs and children them self are an independent risk factor for these malformations. The combination of C677T MTHFR polymorphism and low folate status is associated with a greater risk for NTDs than either variable alone (21).

Folic acid deficiency, MTHFR, hyperhomocysteinemia, vita$\min$ B12

The enzyme 5,10-methylenetetrahydrofolate reductase (MTHFR) converts folate to its active form 5-methyltetrahydrofolate, which together with vitamin B12 participates in the conversion of homocysteine to methionine (Fig. 4). Vitamin B 12 represents essential cofactor of MTHFR. Disturbances in methylation cycle (folate cycle and homocysteine cycle) may result in hypomethylation of DNA, chromosomal instability and breaks. The C677T single nucleotide polymorphism (Ala222 Val) in the MTHFR gene results in thermolabile variant with $40 \%$ reduction of enzyme activity in heterozygote form $(677 \mathrm{CT})$ and $70 \%$ reduction in homozygote form of MTHFR (677TT). The enzyme variants cannot effectively catalyze the conversion of 5,10-methylene tetrahydrofolate (THF) to 5-methylTHF, i.e. the methyl donor for methionine synthase with further decreased level of active tetrahydrofolate in the cells and increased level of homocysteine. Low maternal red blood cell folate has been associated with higher risk of neural tube defect pregnancy (22). Metaanalysis has proven the association of polymorphism C677T MTHFR with higher risk factor for neural tube defects in Europe (23). Second common polymorphism A1298C MTHFR (Glu429Ala) has been associated with NTDs in some populations.

\section{Prevention of NTDs}

Quality of life with neural tube defects has improved in last few decades, though complications accompanying everyday are serious, often even life threatening. Large intervention trials conducted in late 1980s and early 1990s have studied occurrence of congenital anomalies after folic acid supplementation periconceptionally (i.e. 2 to 3 months before and until the end of first trimester). The main findings of these trials were $71-91 \%$ reduction of NTDs recurrence (24) and 41-93\% reduction in the first occurrence of NTDs depending on the incidence of NTDs (25, 26). These intervention trials showed the efficacy of multivitamin containing folic acid in the reduction of other structural anomalies as well, mainly congenital heart defects (25-50\%), urinary tract malformations and others.

The aim of the present study was to investigate the knowledge about folic acid among pregnant women in Slovakia, Bratislava. The authors focused on the changes in eating habits before and during pregnancy, periconceptional recommendations and aware- ness about these recommendations, knowledge about preventive effect of folic acid on birth defects and other diseases in five years period (2004 and 2009).

\section{Methods}

Pregnant women were recruited to the study before a routine ultrasound examination at their local obstetrician. The participants were asked to fulfil questionnaire about following data: pregnancy details, expert advice on nutrition and supplementation during pregnancy, preferring certain food during pregnancy, chronic diseases, congenital anomalies in the family, etc. The responders were also asked to report their opinion on possible preventive role of nutrition in the aetiology of some diseases including congenital anomalies, as well as the specific role of folic acid. Women were asked to define the sources of folic acid as well. The questionnaire was taken in 2004 and after five years interval, in 2009.

The study included 106 pregnant women in 2004 and in 2009. In addition answers from 24 female students of medical school were also included in both years, leaving a total of 130 respondents.

Statistical analysis was performed by the Pearson's Chi-square $\left(\chi^{2}\right)$ test and Fisher's exact test.

\section{Results}

\section{Characteristics of the study population}

Age distribution of the study population is provided in Table 1. The majority of women in both years were 21 to 35 years old (76.2\% in 2004 and $76.9 \%$ in 2009) including students.

In the group of pregnant women $70 \%$ of the participants already had at least one child, among these 1 child had a congenital anomaly (in 2004). In 2009 there were $64 \%$ mothers and two were mothers of children born with congenital anomaly. Medical students were not pregnant and did not have any children.

\section{Knowledge about folic acid}

The questionnaire taken in 2004 revealed that more than $3 / 4$ of the respondents ( $76 \%$ ) heard about folic acid and $66 \%$ also know which foods are rich on this micronutrient. Nevertheless, only $16 \%$ claimed, they were recommended to use some supplements preventively or were aware of the proper food content during pregnancy. Nobody specified what food or which supplement was the responder recommended to use. In the future $17 \%$ of the women plan to use folic acid. Five years later (in 2009) the respondents claimed that they heard about folic acid in $71 \%, 57 \%$ also knew where folic acid is found. On the other hand up to $37 \%$ claimed that they were advised to take preventively some medications or eat nutritionally proper food, which represents significant increase in comparison to the group of students $(\mathrm{p}<0.012)$. In the next gra-

Tab. 1. Age distribution of the respondents (pregnant women/students).

\begin{tabular}{lcc}
\hline Age (years) & 2004 (number) & 2009 (number) \\
\hline$\leq 20$ & $6 / 0$ & $8 / 0$ \\
$21-35$ & $75 / 24$ & $76 / 24$ \\
$36-50$ & $20 / 0$ & $18 / 0$ \\
$\geq 51$ & $5 / 0$ & $4 / 0$ \\
\hline
\end{tabular}


$\square$ pregnant women in $2004 \quad \square$ pregnant women in 2009

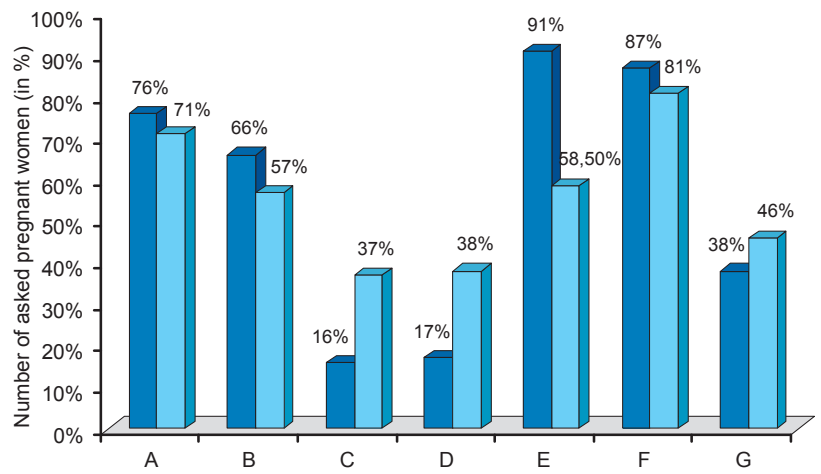

Fig. 5. Knowledge about folic acid - pregnant women results comparison.

A) heard about folic acid; B) know the sources of folic acid; C) were recommended to use supplements or special foods before and during pregnancy; D) plan to use folic acid preventively; E) care about nutrition facts of the foods; $F$ ) agree that by proper food content we may prevent some diseases; $G$ ) agree that by proper food content we may prevent congenital anomalies.

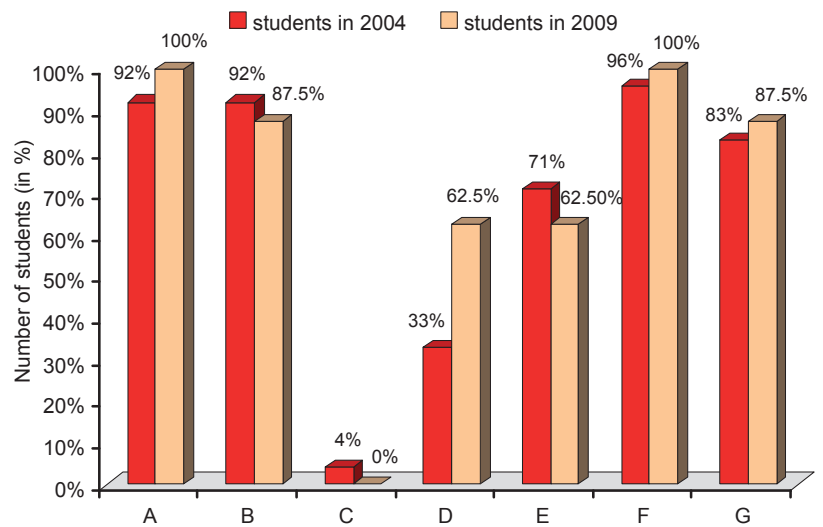

Fig. 6. Knowledge about folic acid - students' results comparison . A) heard about folic acid; B) know the sources of folic acid; C) were recommended to use supplements or special foods before and during pregnancy; D) plan to use folic acid preventively; E) care about nutrition facts of the foods; F) agree that by proper food content we may prevent some diseases; $G$ ) agree that by proper food content we may prevent congenital anomalies.

vidity $38 \%$ of the asked women plan to use folic acid. Ninety one percent were interested in the nutrition facts of the foods and $87 \%$ believed that proper nutrition may prevent some diseases. But only $38 \%$ respondents believe this could prevent congenital anomalies (in 2004). In 2009 the interest about nutrition facts dropped to only $58.5 \%$, only $81 \%$ of the pregnant women believed the preventive effect of the nutrition. However, $46 \%$ respondents said that nutrition may prevent congenital anomalies (Fig. 5).

Medical students, who are expected to be aware of folic acid, heard about this vitamin in $92 \%$ (in 2004). This percentage also knew which food is rich in this vitamin. $33 \%$ of the students would like to use folic acid periconceptionally. In 2009 more than sixty two percent of the students wanted to use folic acid. In 2004 ninety six percent of the student agreed with the statement about possible preventive effect of folic acid on some diseases, and $83 \%$ claimed that also congenital anomalies are preventable by proper food selection, whereas in 2009 it was up to $87.5 \%$ (Fig. 6).

\section{Risk factors causing congenital anomalies}

Among risk factors causing congenital anomalies the pregnant women stated: high maternal age $51 \%$, higher number of gravidity $5 \%$, folic acid deficiency $17 \%$, alcohol $90 \%$, drugs $92 \%$, smoking $92 \%$ (in 2004). In 2009 the risk factors causing congenital anomaly included: high maternal age $47 \%$, number of gravidities $13 \%$, folic acid deficiency $26.5 \%$, alcohol $89 \%$, drugs $98 \%$, smoking $81 \%$ (Fig. 7). In 2004 all the students claimed the risk factors to be alcohol, drugs and smoking. The fact that folic acid deficiency may cause congenital anomalies $83 \%$ of the students agreed, in 2009 it was $88 \%$. There was significant increase in the group of pregnant women thinking that with the higher number of gravidity may cause congenital anomaly in the offspring $(\mathrm{p}<0.016)$ (Fig. 8).

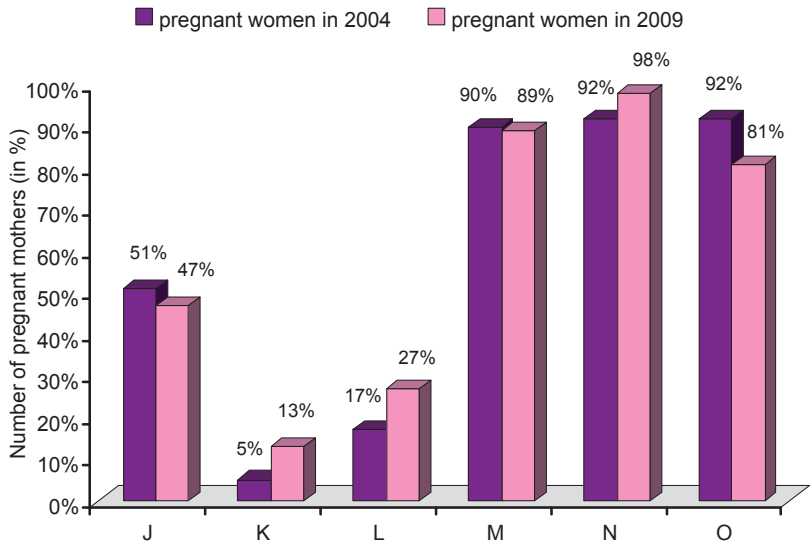

Fig. 7. Risk factors causing congenital anomalies (pregnant women). J) high mother's age; K) number of gravidities; L) folic acid deficiency; M) alcohol; N) drugs; O) smoking.

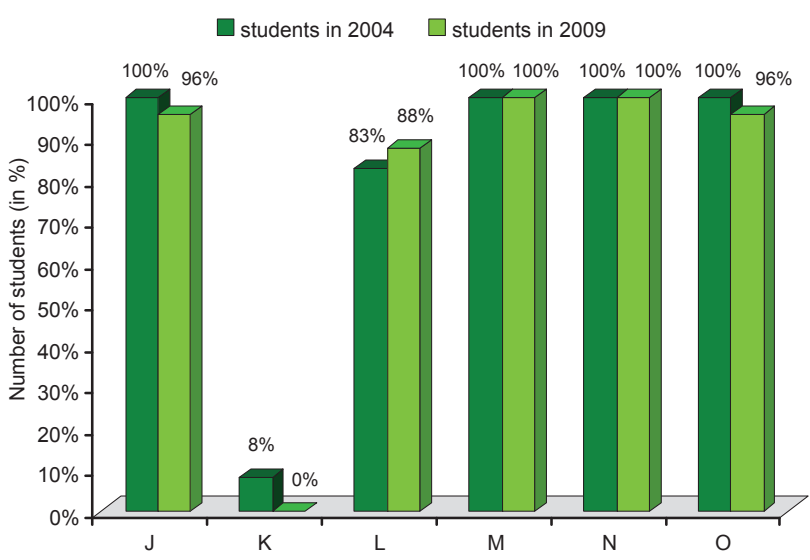

Fig. 8. Risk factors causing congenital anomalies (students).

J) high mother's age; K) number of gravidities; L) folic acid deficiency; M) alcohol; N) drugs; O) smoking. 


\section{Discussion}

May periconceptional folic acid supplementation prevent neural tube defects? The main factor playing role in answering this question is planning the gravidity. Presented survey shows that only $39 \%$ of the gravidities were planned and more-or-less planned in $31 \%$. These results proved that more than $70 \%$ of the women could take folic acid preventively before and during the first months of pregnancy, which is comparable with the western European countries (27). As much as $91 \%$ of the respondents were interested in the nutrition facts of the food, nevertheless only $38 \%$ believe that by correct nutrition we may prevent congenital anomalies (in 2004). Five years later (in 2009) it was $58.5 \%$ and $46 \%$, respectively.

Periconceptional folic acid administration (i.e. 2 to 3 months before and until the end of first trimester) or multivitamin containing folic acid should be advised to all women capable of getting pregnant. The major problem is that only about half of all pregnancies in Slovakia are unplanned. Knowledge of medical staff, common people and especially women of childbearing age about protective effect of folic acid on embryonic development in Slovakia is not sufficient and hence supplementation is not applied in practice. There are four possible ways how to raise folate level in human:

1) Diet: natural foods rich in folates especially green leafy vegetable, beans, citruses, liver, broccoli etc. The usual daily intake of folates is about $200 \mathrm{mg}$ per day in Slovakia (28) and this consumption is not significantly higher in other developed countries. Higher intake of folates may be seen in vegetarian food which, on the other hand, lacks vitamin B12. Generally, diet rich in folates is important for the prevention of NTDs but cannot alone completely neutralize the genetic predisposition for this congenital anomaly (29).

2) Supplements containing folic acid (synthetic form of folates) alone or as part of the multivitamins: Experts in the USA recommended that 'all women of childbearing age who are capable of becoming pregnant should consume $4 \mathrm{OO}$ micrograms of folic acid per day for the purpose of reducing their risk of having a pregnancy affected by spina bifida or other NTD' in addition to diet rich on natural folates (30). Folic acid supplementation has positive effect on intrauterine embryo development only if started before conception to raise lever of red blood cell folate.

3) Folic acid must be reduced to the metabolically active form - tetrahydrofolate. 5-methyl-tetrahydrofolate (5-methyl-THF) is the predominant form of dietary folate found in circulation and is the metabolic form transported into peripheral tissues for cellular metabolism. It is also available commercially as a crystalline form of the calcium salt - metafolin. This form may be used either alone or as part of the multivitamins. Recently U.S. food and drug administration (FDA) approved oral contraception metafolin for the purpose of reducing the risk of neural tube defect in a pregnancy conceived while taking contraception or shortly after discontinuing (31).

4) Food fortification: In 1997 USA and Canada, later Chile initiated flour fortification with folic acid. Their decision was influenced by news that folic acid may reduce not only occurrence of congenital anomalies but also may lower the level of hyperhomocysteinemia and reduce the risk of cardiovascular diseases, cancer and improve cognitive functions in elderly. Another important benefit of flour fortification with folic acid is that fortification enables higher intake of this vitamin in all socioeconomic classes.

For the purpose of reduction of recurrent NTDs it is advised to take $4 \mathrm{mg}$ of folic acid per day periconceptionally. After the 3rd month of pregnancy it is recommended to continue with 400 $\mu \mathrm{g}$ of folic acid per day until the 10th-12th week after delivery. Higher dosage of folic acid ( $4 \mathrm{mg}$ per day) is suggested in addition to women with epilepsy, insulin dependent diabetes mellitus and women with obesity (BMI over $35 \mathrm{~kg} / \mathrm{m}^{2}$ ), who are at higher risk of bearing a child with congenital malformation (30).

\section{Conclusion}

The prevention of NTD is much better than the medical care. Especially in situation, when the only approach is elective termination of pregnancy after prenatal diagnosis of NTD in foetus. The results of the study revealed low knowledge about effect of folic acid on developing embryo among women of childbearing age. Effective intervention programs are needed with the aim to improve periconceptional intake of folic acid.

\section{References}

1. Zdravotnícka ročenka Slovenskej republiky 2007. Bratislava: Národné centrum zdravotníckych informácií, 2008; 1-72.

2. Boyles AL, Billups AV, Deak KL et al. Neural tube defects and folate pathway genes: family-based association tests of gene-gene and geneenvironment interactions. Environ Health Perspect 2006; 114 (10): 1547-1552.

3. McComb JG. Spinal and cranial neural tube defects. Semin Pediatr Neurol 1997; 4 (3): 156-166.

4. Horn F. Spina bifida. Kaudálne defekty neurálnej rúry. Prešov: VMV, 2005: 1-96.

5. Pekarovič E: Diagnosis of urinary tract disorders in congenital spinal lesions. Int Urol Nephrol 1974; 6 (3-4): 183-189.

6. Horn F, Babala J, Smrek M et al. V akom veku operovat' pacientov so spinálnym lipómom? Čes-slov Pediat 1999; 54 (11): 632-634.

7. Van der Put NM, van Straaten HW, Trijbels FJ, Blom HJ. Folate, homocysteine and neural tube defects: an overview. Exp Biol Med 2001; 226 (4): 243-270.

8. Kapeller K, Pospíšilová V. Embryológia človeka. 2nd eddition. Martin: Osveta, 2001, 1-371.

9. Volcik KA, Blanton SH, Kruzel MC et al. Testing for genetic associations in a spina bifida population: Analysis of HOX gene family and human candidate gene regions implicated by mouse models of neural tube defects. Am J Med Gen 2002; 110 (3): 203-207.

10. Levitt MA, Patel M, Rodriguez G, Gaylin DS, Pena A. The tethered spinal cord in patients with anorectal malformations. J Pediatr Surg 1997; 32 (3): 342-368.

11. Golonka NR, Haga LJ, Keating RP et al. Routine MRI evaluation of low imperforate anus reveals unexpected high incidence of tethered spinal cord. J Pediatr Surg 2002; 37 (7): 966-969. 
12. Weaver KB, Matthews H, Chegini $S$ et al. Vertebral column and spinal cord malformation in children with exstrophy of the cloaca, with emphasis on their functional correlates. Teratology 1997; 55 (4): 241-248.

13. McLone DG. The etiology of neural tube defects: the role of folic acid. Child Nerv Syst 2003; 19 (7-8): 537-539.

14. Swain S, Agrawal A, Bhatia BD. Congenital malformations at birth. Indian Pediatr 1994; 31 (10): 1187-1191.

15. Marini NJ, Hoffmann TJ, Lammer EJ et al. A Genetic Signature of Spina Bifida Risk from Pathway-Informed Comprehensive Gene-Variant Analysis. PLoS ONE 2011; 6 (11): e28408.

16. Zhu HP, Barber R, Shaw GM et al. Is sonic hedgehog pilot (SHH) a candidate gene for spina bifida? A pilot study. Am J Med Genet 2003; 117 (1): 87-88.

17. Wallingford JB, Harland RM. Neural tube closure requires Dishevelled-dependent convergent extension of the midline. Development 2002; 129 (24): 5815-5825.

18. Simons M, Mlodzik M. Planar cell polarity signaling: from fly development to human disease. Annu Rev Genet 2008; 42: 517-540.

19. Kibar Z, Torban E, McDearmid R et al. Mutations in VANGL1 Associated with Neural-Tube Defects. N England Med 2007; 356 (14): 1432-1437.

20. Bartsch O, Thiede A, Lechno S et al. VANGL1 gene mutations identified in 100 patients with neural tube defects from Slovakia, Romania, and Germany. Hamburg, March 2-4 2010. Ger Hum Gen Meet. Abstracts. Available on internet: ttp://gfhev.de/de/kongress/2010_abstracts.pdf

21. Christensen B, Arbour L, Tran P et al. Genetic polymorphisms in methylenetetrahydrofolate reductase and methionine synthase, folate levels in red blood cells, and risk of neural tube defects. Am J Med Genet 1999; 84 (2): 151-157.

22. Relton CL, Wilding CS, Laffling AJ et al. Low erythrocyte folate status and polymorphic variation in folate-related genes are associated with risk of neural tube defect pregnancy. Mol Genet Metab 2004; 81 (4): 273-281.
23. Amorim MR, Lima MA, Castilla EE et al. Non-Latin European descent could be a requirement for association of NTDs and MTHFR variant 677C > T: a meta-analysis. Am J Med Genet A 2007; 143 (15): 1726-1732.

24. MRC Vitamin Study Research Group: Prevention of neural tube defects: results of the Medical Research Council Vitamin Study. Lancet 1991; 338: 131-137.

25. Berry RJ, Li Z, Erickson JD et al. Prevention of neural-tube defects with folic acid in China: China-US Collaborative Project for Neural Tube Defect Prevention. N Engl J Med 1999; 341: 1485-1490.

26. Czeizel AE, Dobó M, Vargha P. Hungarian cohort controlled trial of periconceptional multivitamin supplementation shows a reduction in certain congenital abnormalities. Birth Defects Res A Clin Mol Teratol 2004; 70: 853-861.

27. Nilsen RM, Vollset SE, Gjessing HK et al. Patterns and predictors of folic acid supplement use among pregnant women: the Norwegian Mother and Child Cohort Study. Am J Clin Nutr 2006; 84 (5): 1134-1141.

28. Krajčovičová-Kudláčková M, Blažíček P. Nutričné determinant homocysteinémie. Čas Lek ces 2002; 141 (13): 417-420.

29. Czeizel AE, Dudas I, Paput L, Banhidy F. Prevention of Neural-Tube Defects with Periconceptional Folic Acid, Methylfolate, or Multivitamins? Ann Nutr Metab 2011; 58: 263-271.

30. Wilson RD, Johnson JA, Wyatt $P$ et al. Pre-conceptional Vitamin/ Folic Acid Supplementation 2007: The Use of Folic Acid in Combination With a Multivitamin Supplement for the Prevention of Neural Tube Defects and Other Congenital Anomalies. J Obstet Gynaecol Can 2007; 29 (12): 1003-1013.

31. Taylor TN, Farkouh RA, Graham JB et al. Potential reduction in neural tube defects associated with use of Metafolin-fortified oral contraceptives in the United States. Am J Obstet Gynecol 2011; 205 (5): 460.e1-8.

Received February 29, 2012. Accepted October 27, 2013. 